\title{
Peptoid helix displaying flavone and porphyrin: Synthesis and intramolecular energy transfer
}

Woojin Yang, ${ }^{\dagger}$ Junhyuk Jo, ${ }^{\dagger}$ Hyeongyeol Oh, ${ }^{\dagger}$ Hohjai Lee, ${ }^{*}$ Won-jin Chung, ${ }^{*}$ Jiwon Seo*

Department of Chemistry, School of Physics and Chemistry, Gwangju Institute of Science and Technology, 123

Cheomdan-gwagiro, Buk-gu, Gwangju 61005, South Korea.

*Corresponding author:

jseo@gist.ac.kr (J. Seo), wjchung@gist.ac.kr (W.-j. Chung), hohjai@gist.ac.kr (H. Lee)

†These authors contributed equally to this work.

\section{$\underline{\text { Table of contents }}$}

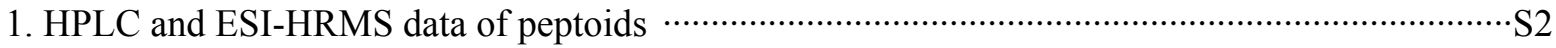

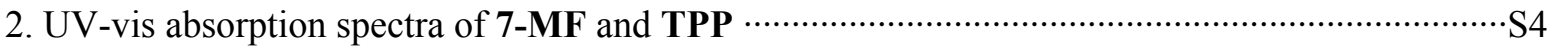

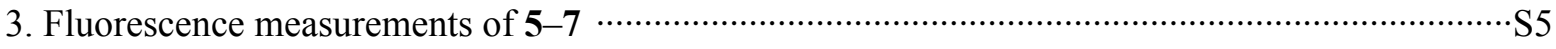

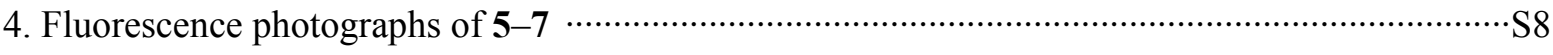

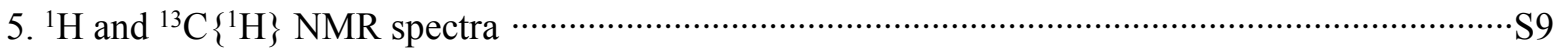




\section{HPLC and ESI-HRMS data of peptoids}
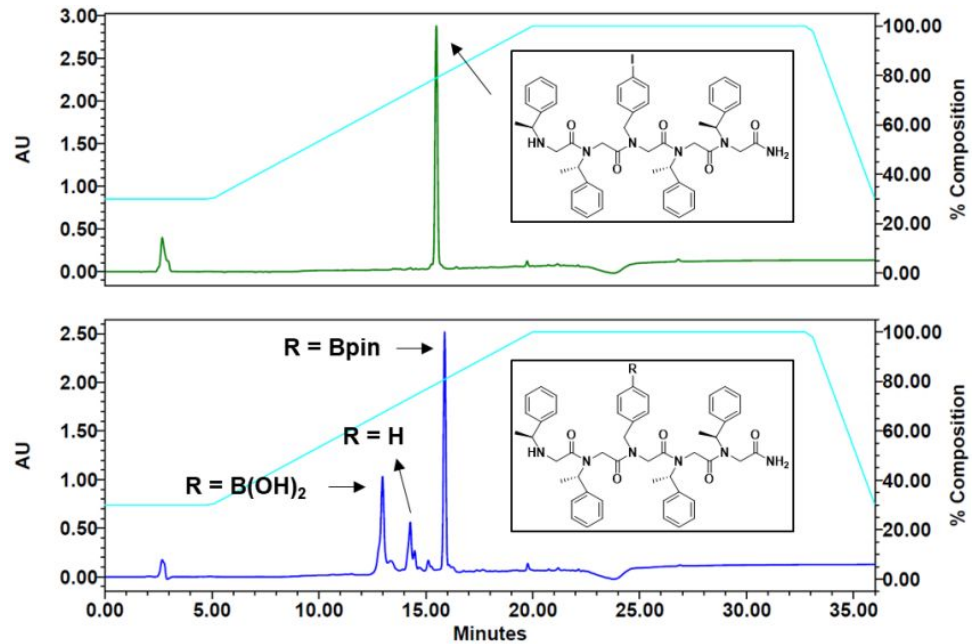

Figure S1. HPLC chromatograms of crude peptoids before and after Miyaura borylation, monitored at $220 \mathrm{~nm}$.
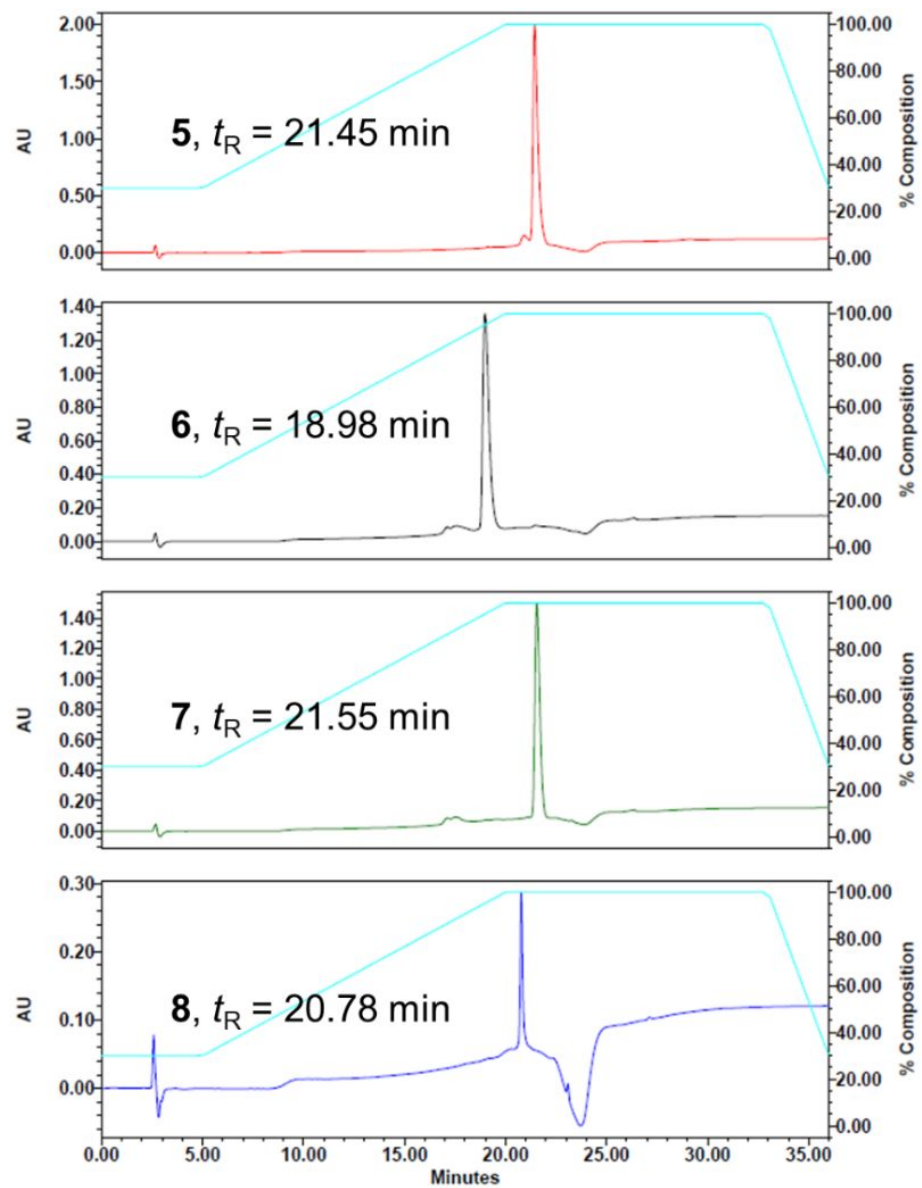

Figure S2. HPLC chromatograms of peptoids monitored at $220 \mathrm{~nm}$ ( $>97 \%$ purity). The retention times $\left(t_{\mathrm{R}}\right)$ are shown. 


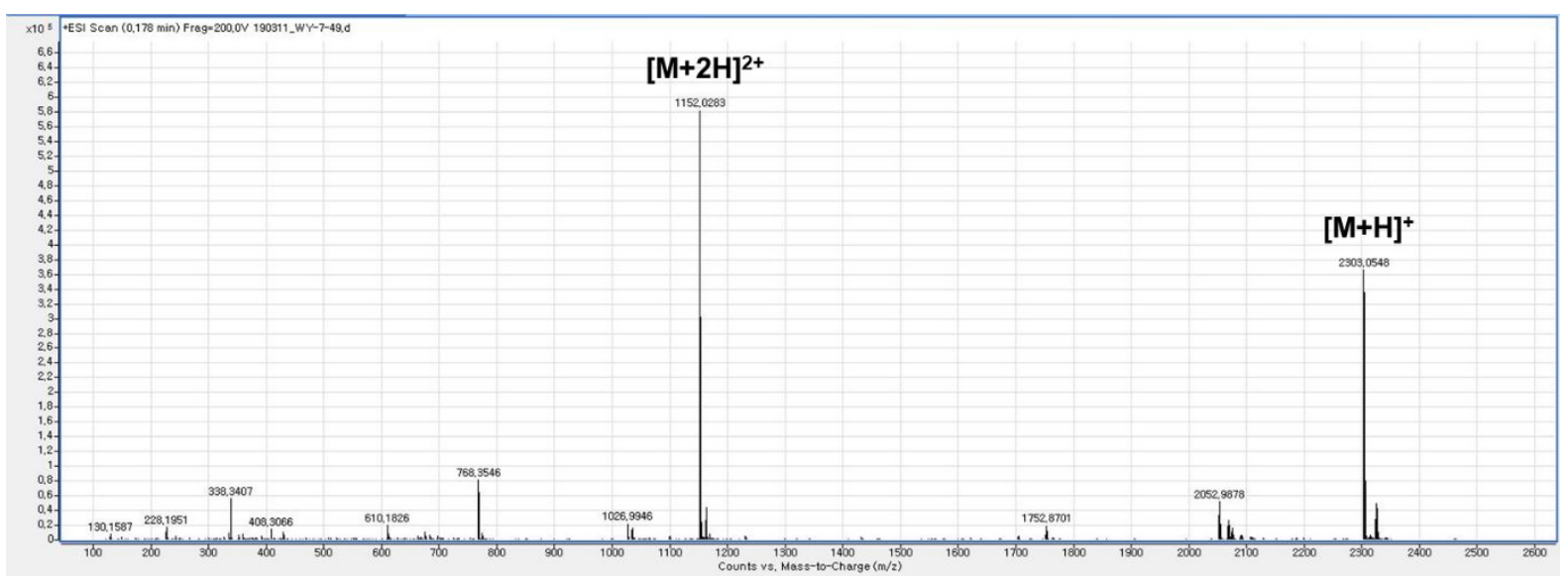

Figure S3. HRMS (ESI) spectra of $\mathbf{5}$.

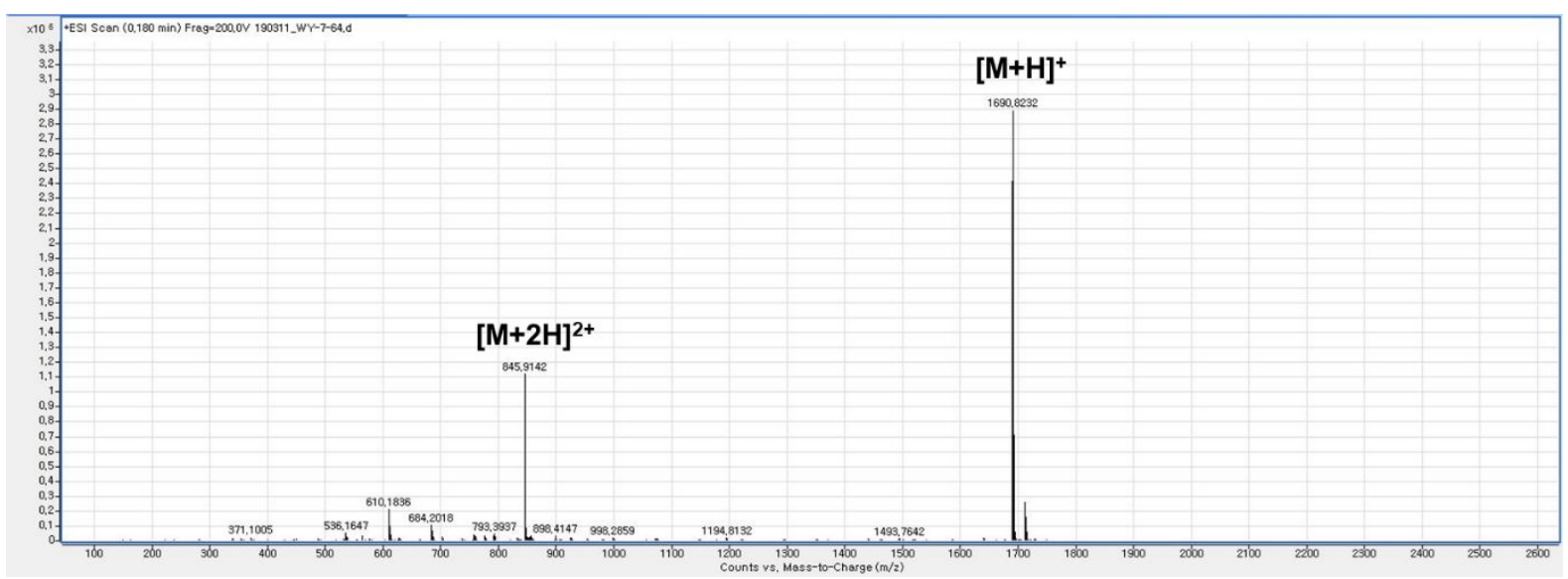

Figure S4. HRMS (ESI) spectra of 6.

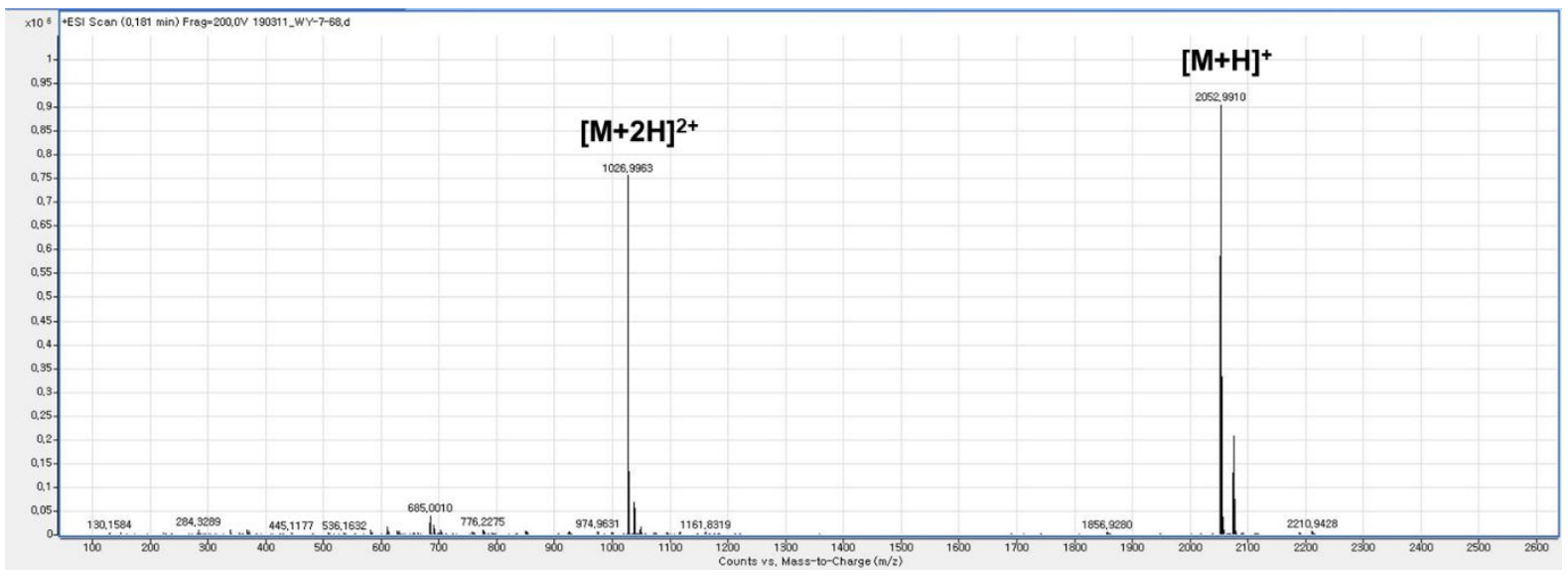

Figure S5. HRMS (ESI) spectra of 7. 


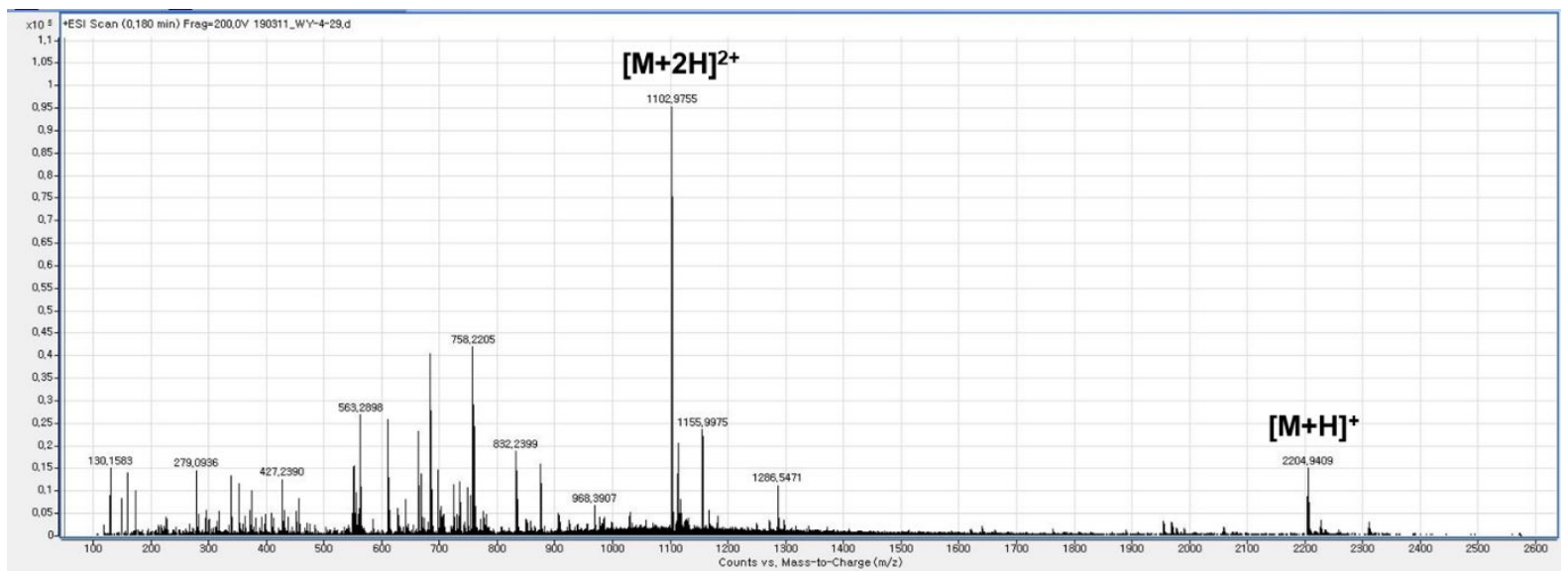

Figure S6. HRMS (ESI) spectra of 8.

\section{UV-vis absorption spectra of 7-MF and TPP}

(a)

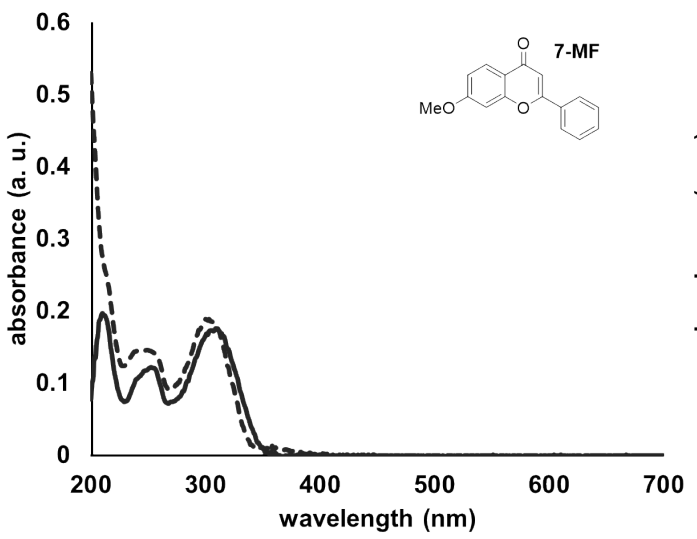

(b)

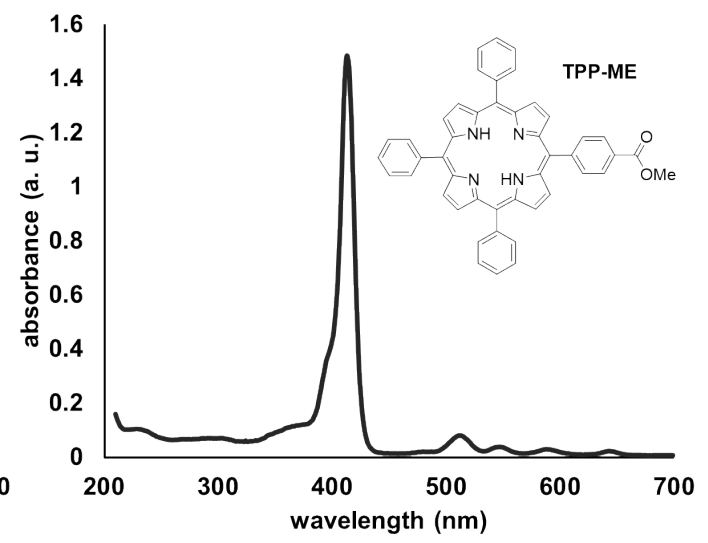

Figure S7. UV-vis absorption spectra of 7-methoxyflavone (7-MF) and TPP-ME at $20{ }^{\circ} \mathrm{C}$. (a) 7Methoxyflavone (50 $\mu \mathrm{M}$, solid line: in $\mathrm{MeCN} / \mathrm{MeOH}(1: 1, \mathrm{v} / \mathrm{v})$, dashed line: in MeCN), (b) TPP-ME $(50 \mu \mathrm{M}$, in $\mathrm{MeCN} / \mathrm{MeOH}(1: 1, \mathrm{v} / \mathrm{v}))$. TPP-ME in $\mathrm{MeCN}$ is not shown due to poor solubility. 


\section{Fluorescence measurements of $5-7$}

\begin{tabular}{ccc}
\hline & $\mathrm{MeCN}$ & $\mathrm{MeCN} / \mathrm{MeOH}(1: 1, \mathrm{v} / \mathrm{v})$ \\
\hline TPP emission enhancement & 1.47 & 2.11 \\
7-MF emission decrease & 0.35 & 0.016
\end{tabular}

Table S1. Change in emission of TPP and 7-MF of FPPC 5 compared to 7 and 6, respectively. The values are calculated using the absolute areas of the emission bands shown in Table S2.

\begin{tabular}{cccc}
\hline \multicolumn{2}{c}{ emission band } & \multicolumn{2}{c}{ solvent } \\
\hline \hline pigment & peptoid & MeCN & $\begin{array}{c}\mathrm{MeCN} / \mathrm{MeOH} \\
(1: 1, \mathrm{v} / \mathrm{v})\end{array}$ \\
\hline \hline \multirow{2}{*}{$7-\mathrm{MF}$} & $\mathbf{5}$ & $6.2359 \mathrm{e}+05$ & $6.0891 \mathrm{e}+06$ \\
\cline { 2 - 4 } & $\mathbf{6}$ & $1.7899 \mathrm{e}+06$ & $3.7907 \mathrm{e}+08$ \\
\cline { 2 - 4 } & $\mathbf{7}$ & $2.8343 \mathrm{e}+05$ & $3.8930 \mathrm{e}+05$ \\
\hline \multirow{2}{*}{ TPP } & $\mathbf{5}$ & $1.2129 \mathrm{e}+08$ & $1.8707 \mathrm{e}+08$ \\
\cline { 2 - 4 } & $\mathbf{6}$ & $9.6685 \mathrm{e}+04$ & $2.0810 \mathrm{e}+06$ \\
\hline & $\mathbf{7}$ & $8.2303 \mathrm{e}+07$ & $8.8680 \mathrm{e}+07$
\end{tabular}

Table S2. The absolute areas of the emission bands of 7-MF and TPP in 5, 6, and $\mathbf{7}$ in MeCN and $\mathrm{MeCN} / \mathrm{MeOH}(1: 1, \mathrm{v} / \mathrm{v})$. Areas of the emission bands of 7-MF and TPP were integrated in the range of 350-615 nm and 615-800 nm, respectively. The baseline subtraction was conducted with a peptoid without pigments. 

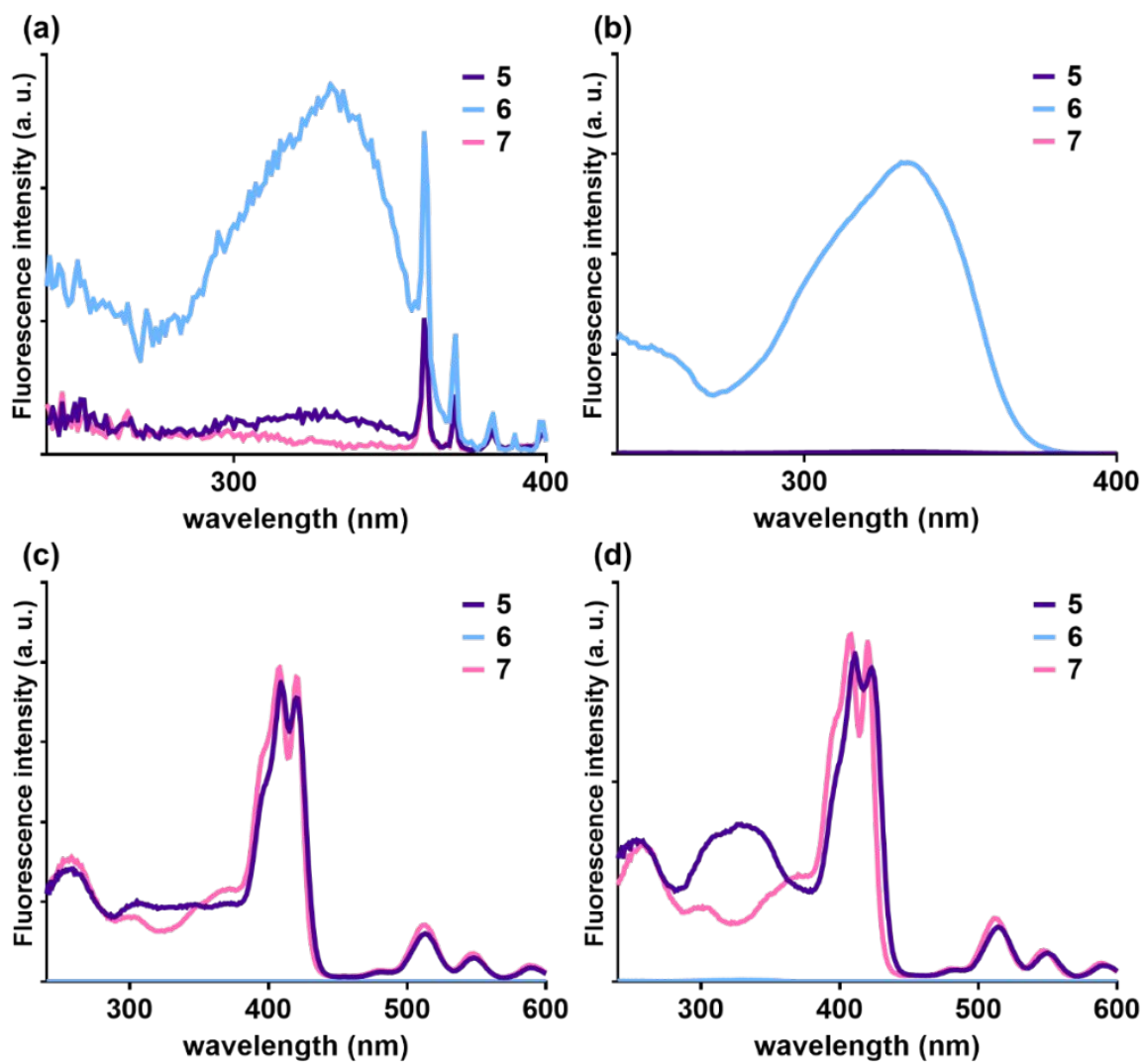

Figure S8. Fluorescence excitation spectra of 5-7 $(5 \mu \mathrm{M})$. Excitation spectra at 7-MF specific emission wavelength (a) $\lambda_{\mathrm{em}}=405 \mathrm{~nm}$ in $\mathrm{MeCN}$ and (b) $\lambda_{\mathrm{em}}=425 \mathrm{~nm}$ in $\mathrm{MeCN} / \mathrm{MeOH}(1: 1, \mathrm{v} / \mathrm{v})$, and at TPP specific emission wavelength $\left(\lambda_{\mathrm{em}}=650 \mathrm{~nm}\right)(\mathrm{c})$ in $\mathrm{MeCN}$ and (d) in $\mathrm{MeCN} / \mathrm{MeOH}(1: 1, \mathrm{v} / \mathrm{v})$. The fluorescence excitation spectra were obtained at the wavelengths where 7-MF and TPP emit maximally to confirm their correlation with the excitation wavelengths, and typical FRET features were observed. 

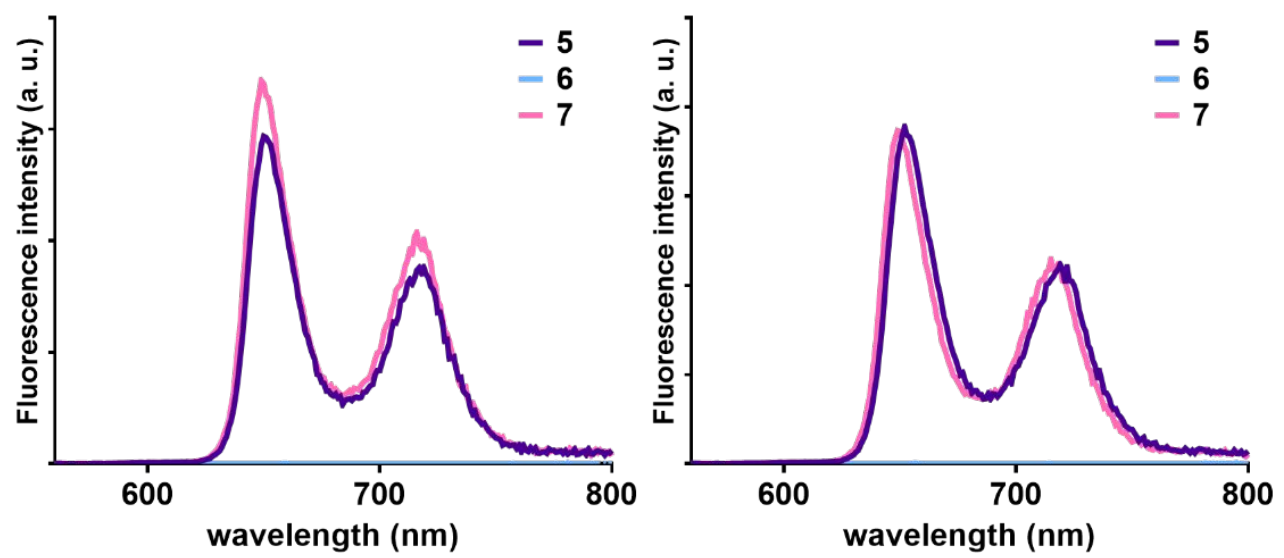

Figure S9. Fluorescence emission spectra of 5-7 $(5 \mu \mathrm{M})$. Emission spectra under porphyrin specific excitation wavelength $\left(\lambda_{\mathrm{ex}}=550 \mathrm{~nm}\right)(\mathrm{a})$ in $\mathrm{MeCN}$ and $(\mathrm{b})$ in $\mathrm{MeCN} / \mathrm{MeOH}(1: 1, \mathrm{v} / \mathrm{v})$.

(a)

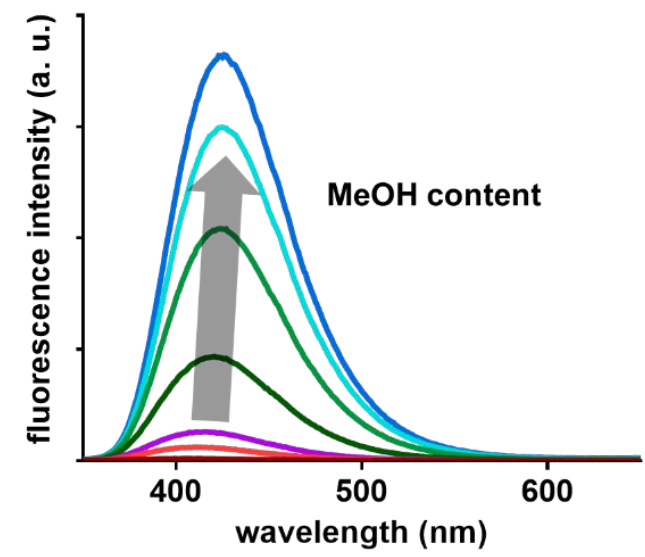

(b)

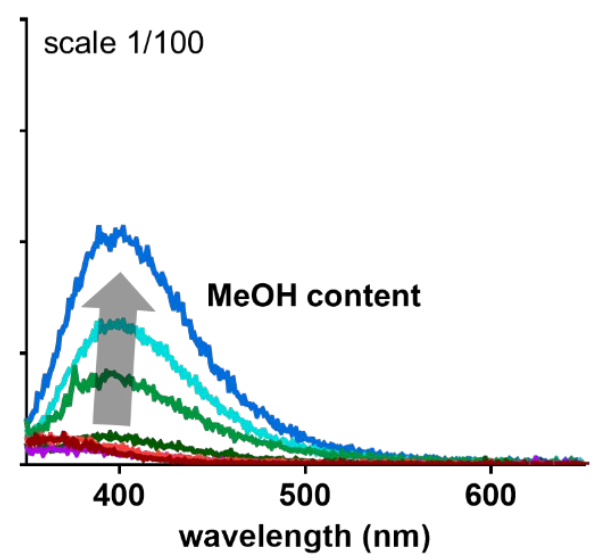

Figure S10. Fluorescence emission spectra of (a) 6 and (b) 7-MF in $\mathrm{MeCN}-\mathrm{MeOH}$ binary solvent. $\mathrm{MeOH}$ contents are as follows: $1 \%$ (red), 5\% (orange), 10\% (violet), 25\% (dark green), $50 \%$ (light green), $75 \%$ (cyan), and 99\% (blue). 
(a)

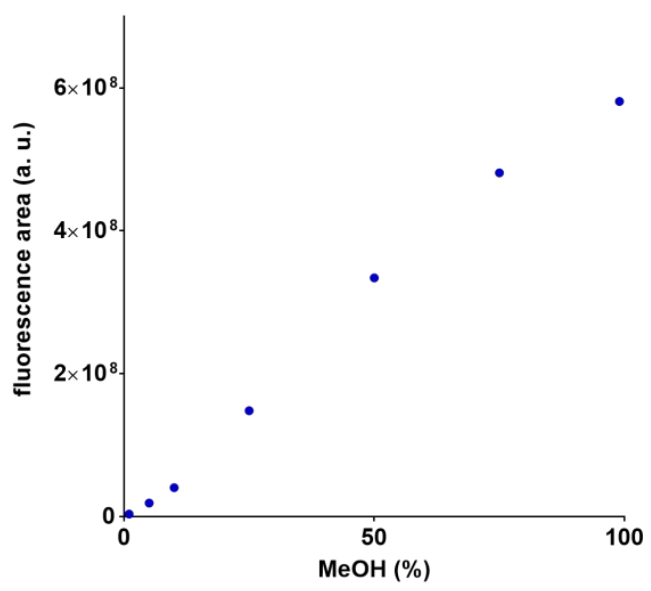

(b)

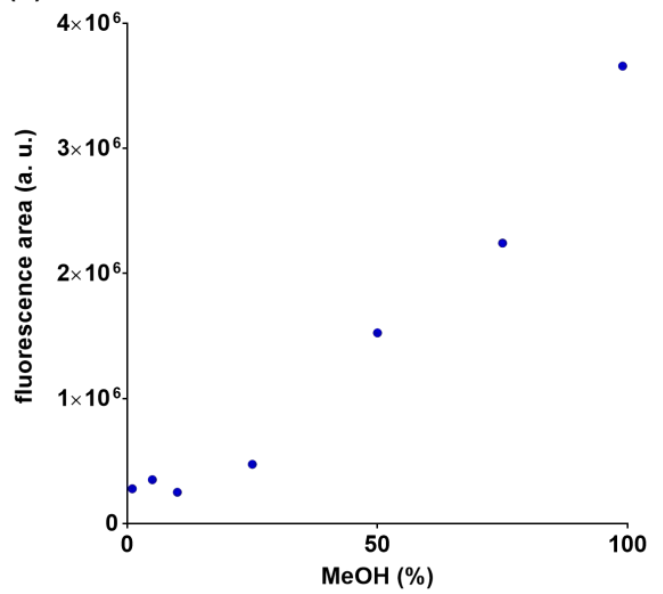

Figure S11. Plot of areas of the emission bands of (a) 6 and (b) 7-MF shown in Figure S10.

\section{Fluorescence photographs of 5-7}

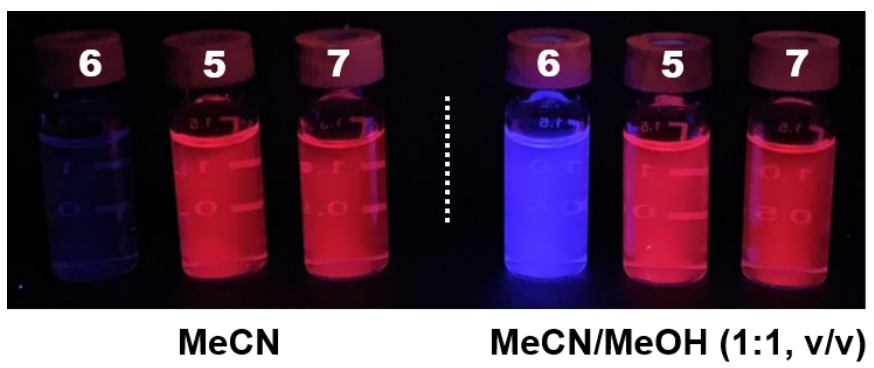

Figure S12. Fluorescent photographs of 5-7 $(5 \mu \mathrm{M})$ obtained in the indicated solvent conditions under a UV lamp (TLC UV lamp, $365 \mathrm{~nm}$ ). 


\section{5. ${ }^{1} \mathrm{H}$ and ${ }^{13} \mathrm{C}\left\{{ }^{1} \mathrm{H}\right\}$ NMR spectra}

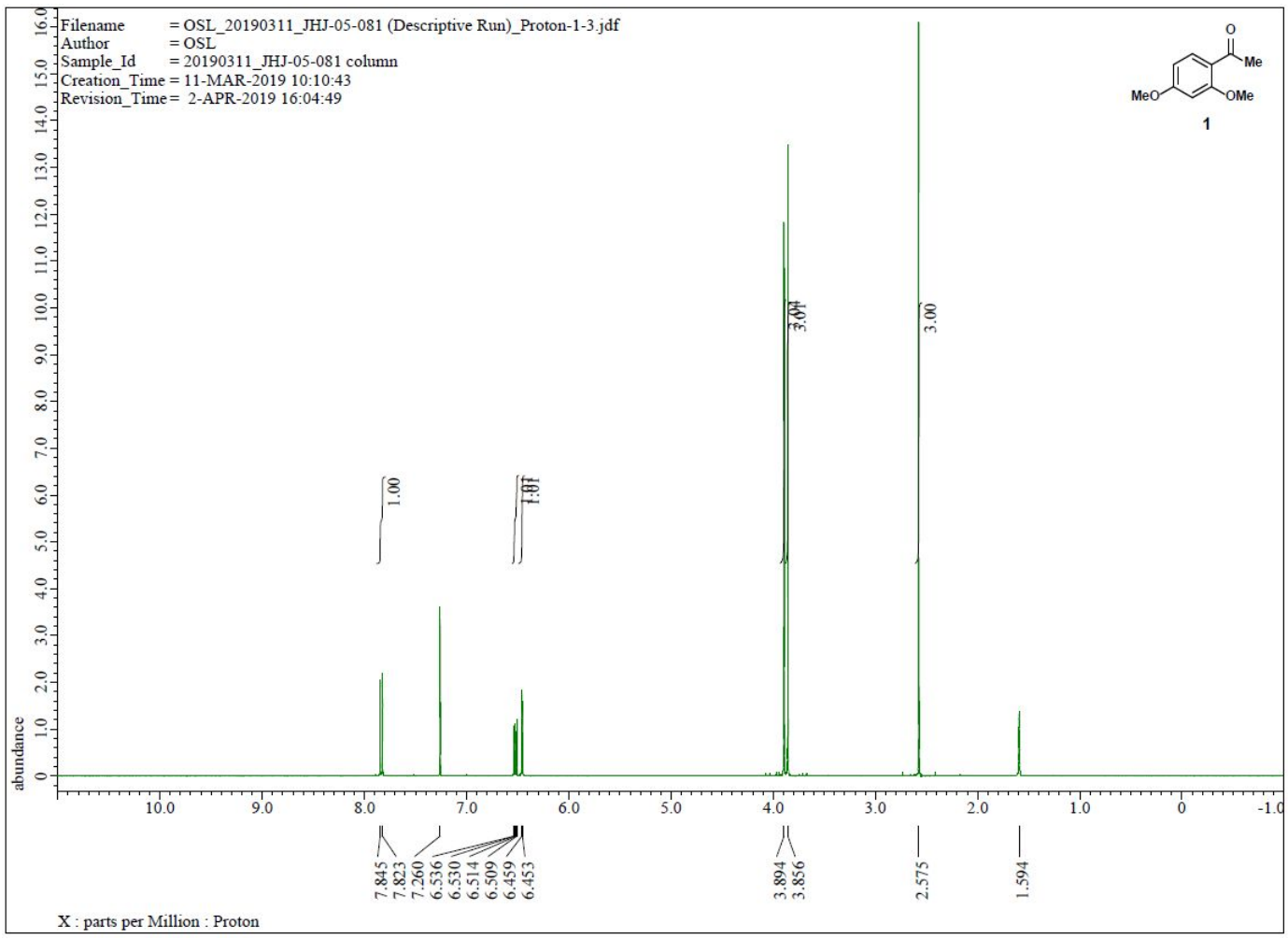

Figure S13. ${ }^{1} \mathrm{H}$ NMR spectrum of $\mathbf{1}$.

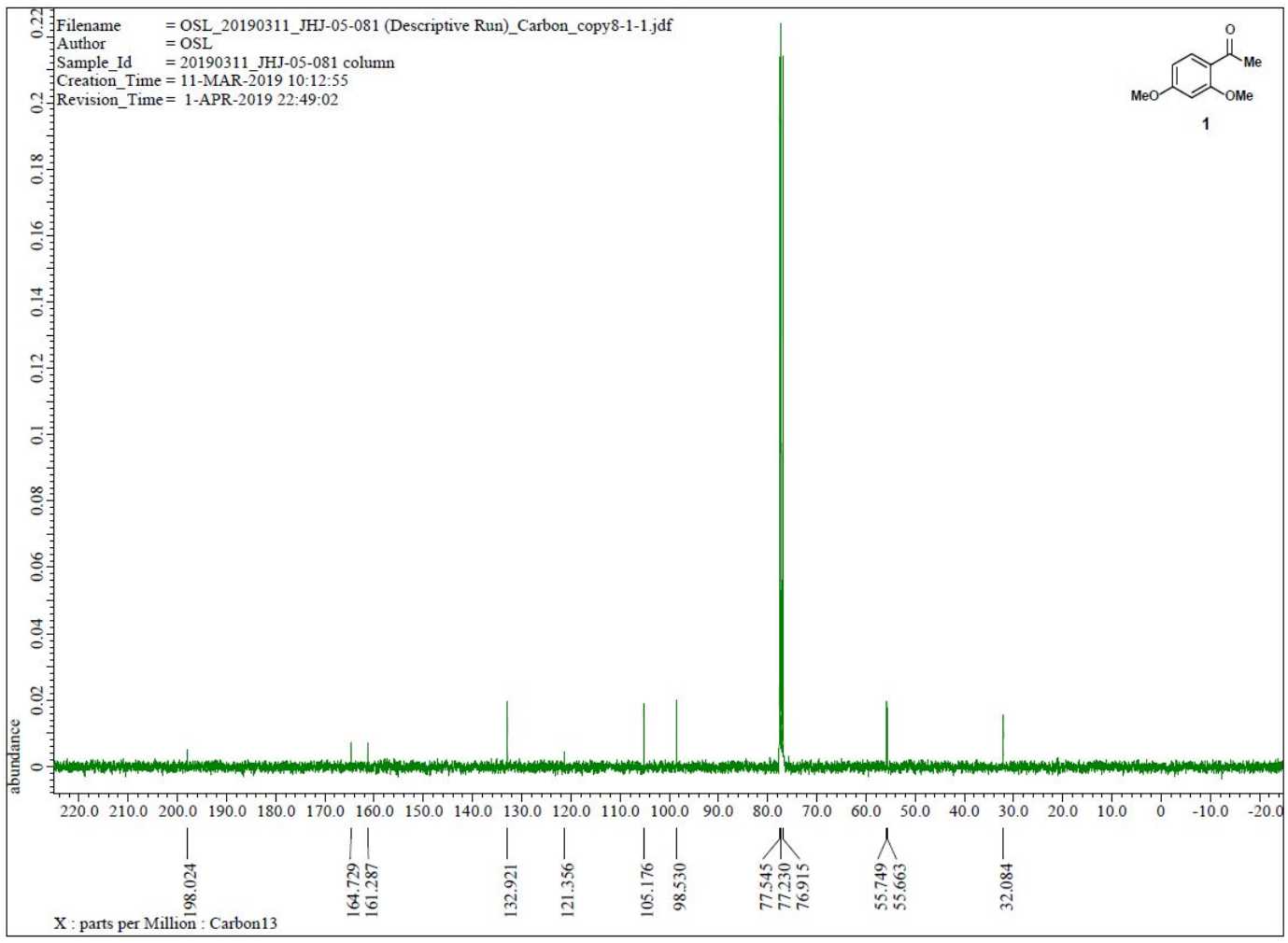

Figure S14. ${ }^{13} \mathrm{C}\left\{{ }^{1} \mathrm{H}\right\}$ NMR spectrum of $\mathbf{1}$. 


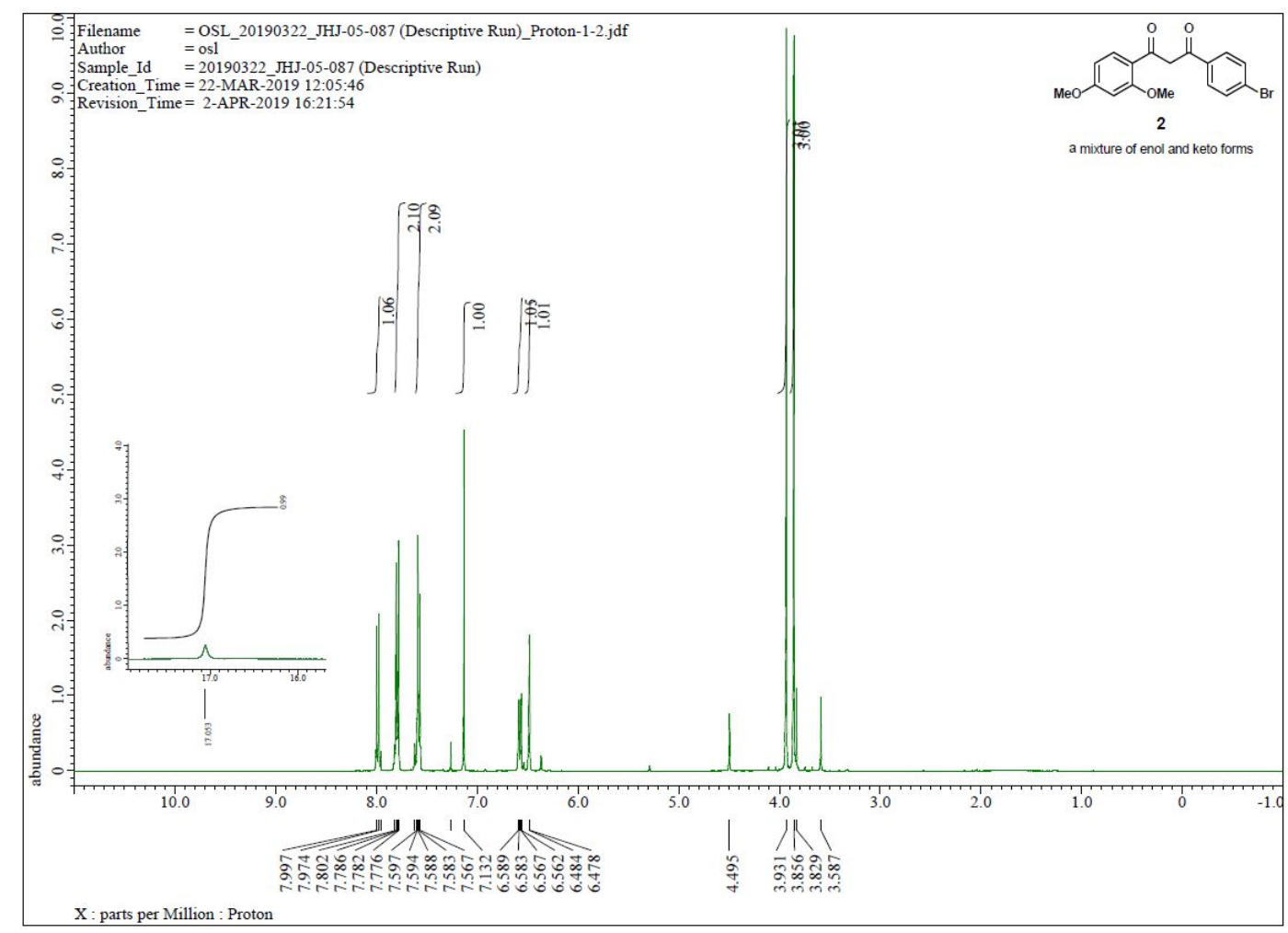

Figure S15. ${ }^{1} \mathrm{H}$ NMR spectrum of 2.

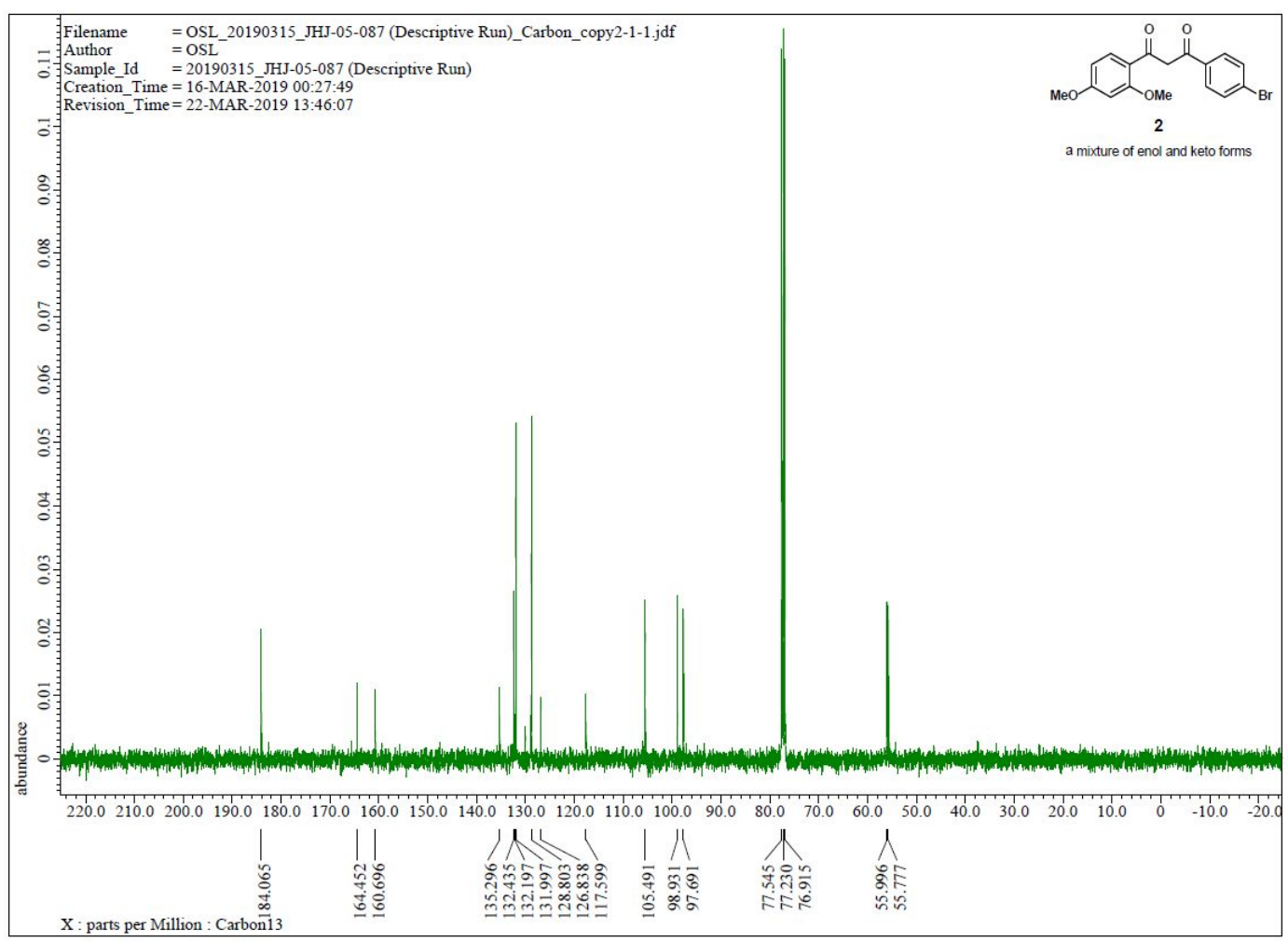

Figure S16. ${ }^{13} \mathrm{C}\left\{{ }^{1} \mathrm{H}\right\}$ NMR spectrum of 2 . 


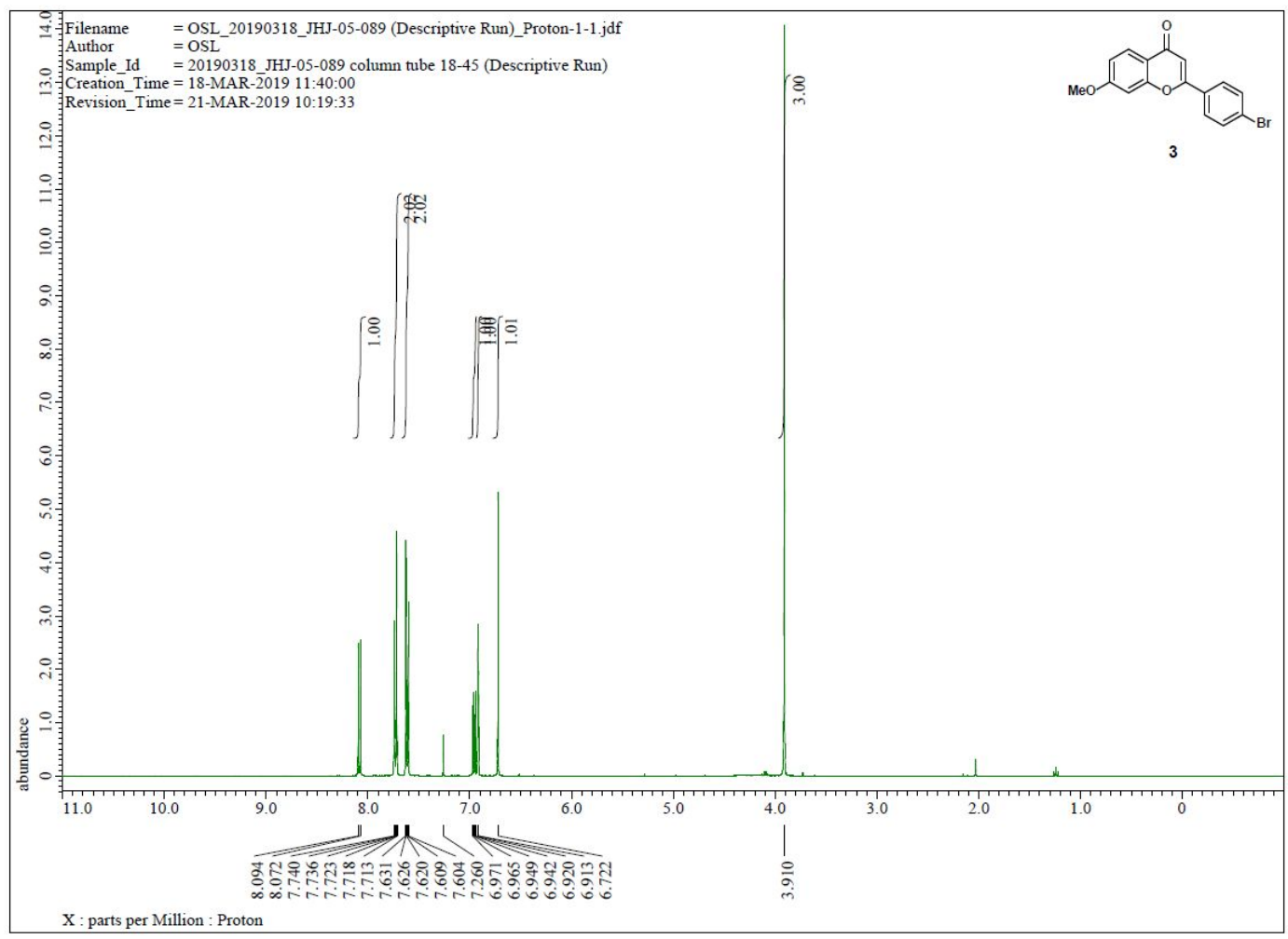

Figure S17. ${ }^{1} \mathrm{H}$ NMR spectrum of 3 .

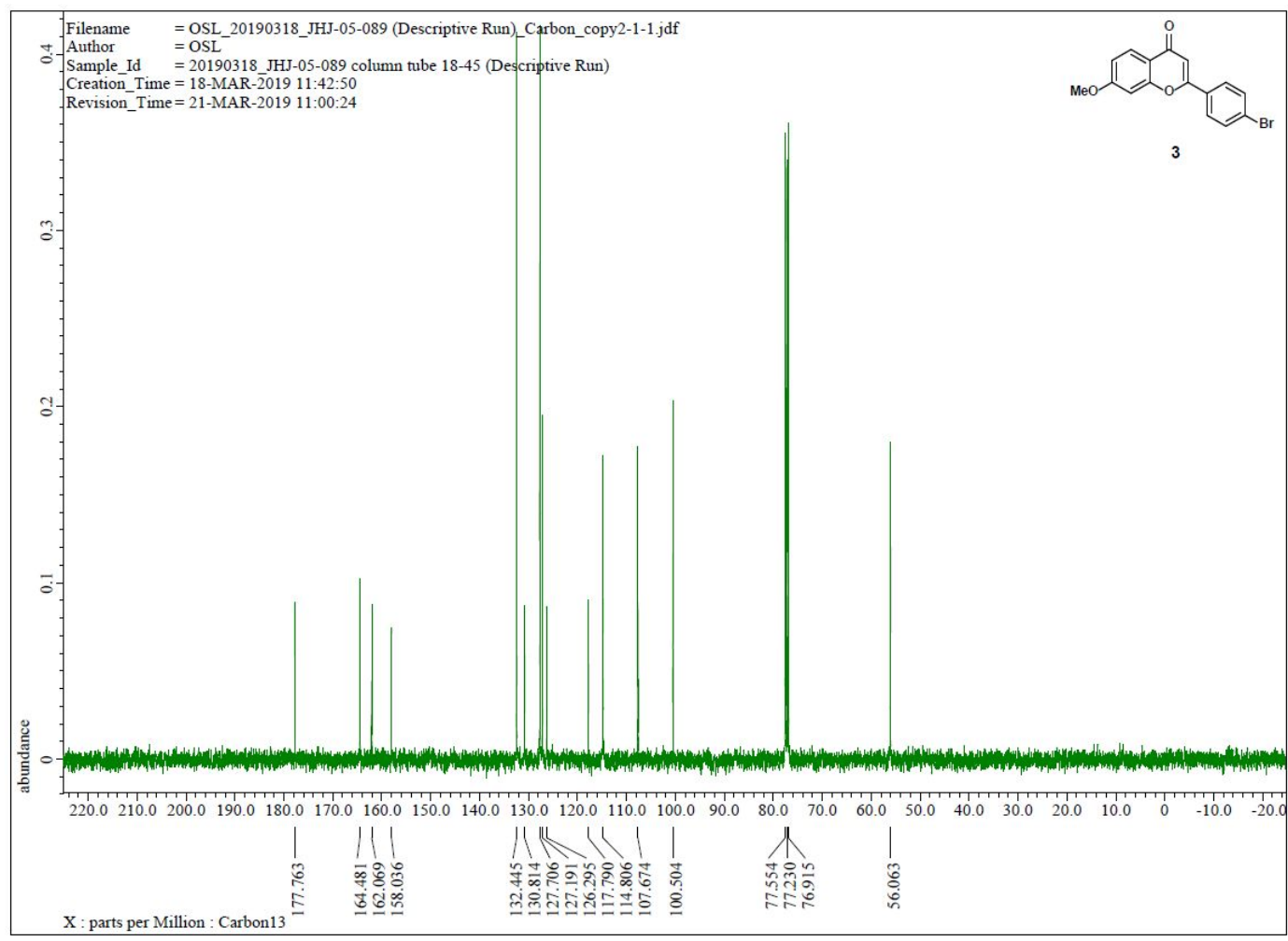

Figure S18. ${ }^{13} \mathrm{C}\left\{{ }^{1} \mathrm{H}\right\}$ NMR spectrum of 3 . 


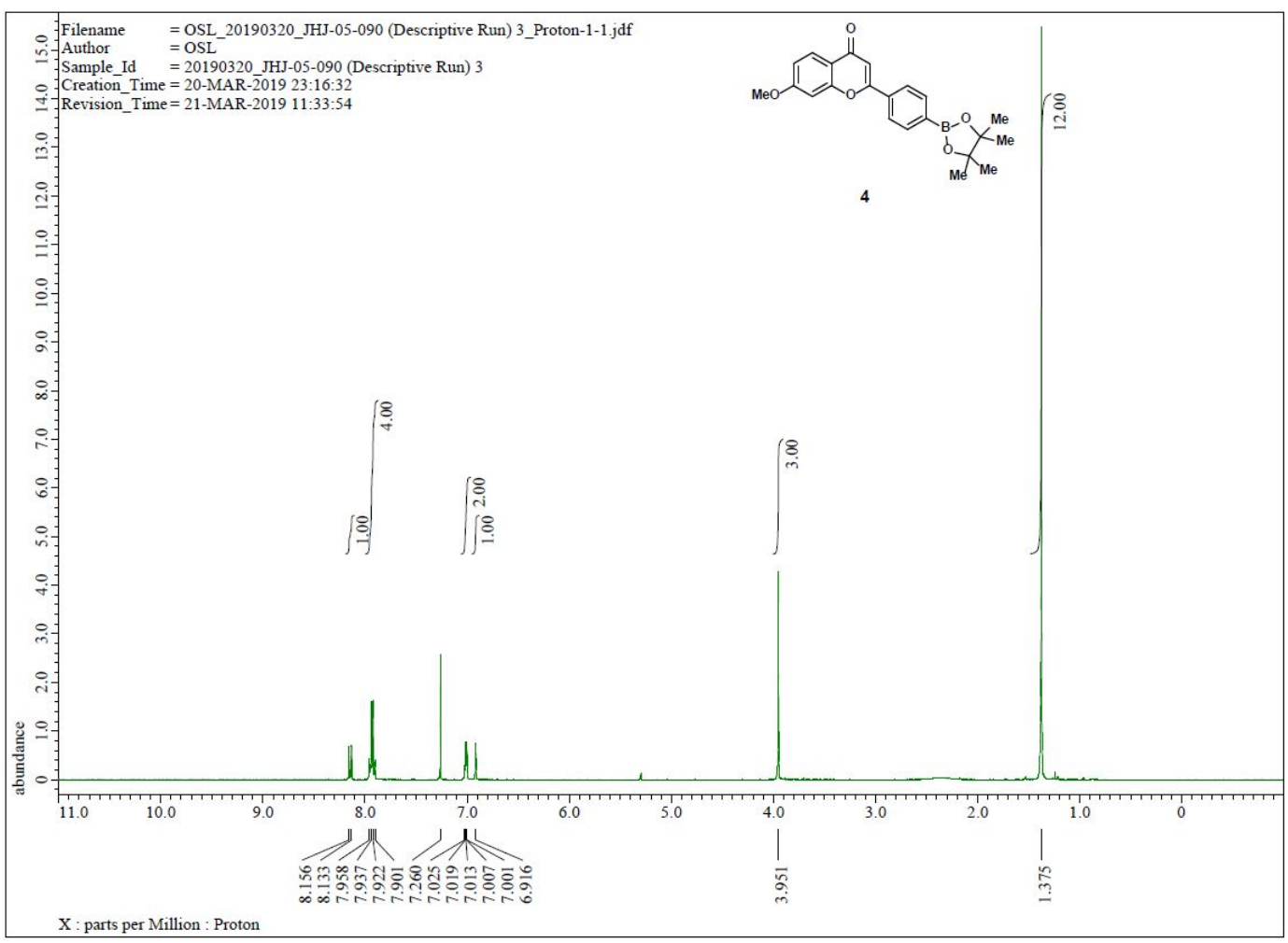

Figure S19. ${ }^{1} \mathrm{H}$ NMR spectrum of 4 .

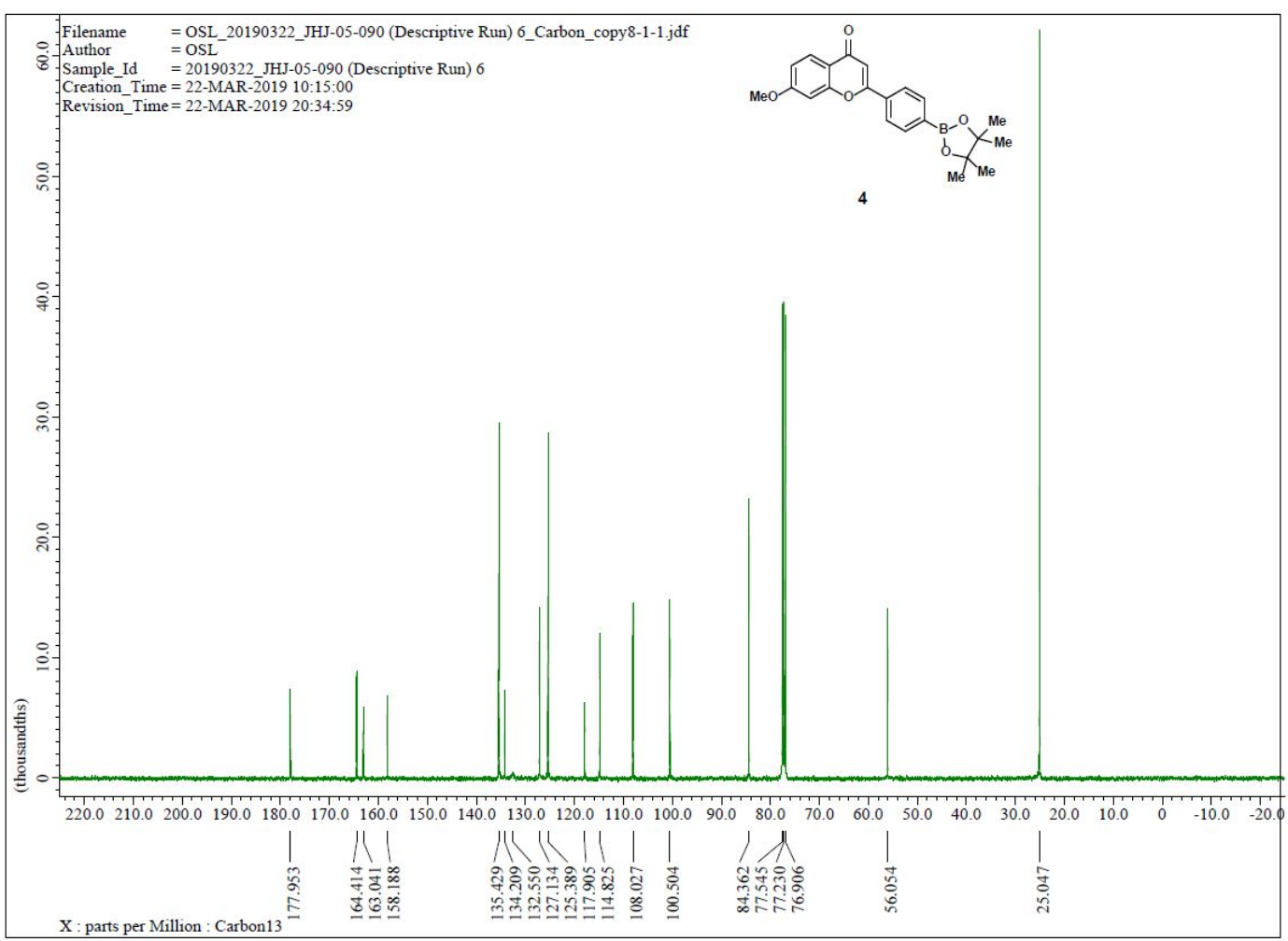

Figure S20. ${ }^{13} \mathrm{C}\left\{{ }^{1} \mathrm{H}\right\}$ NMR spectrum of 4 . 


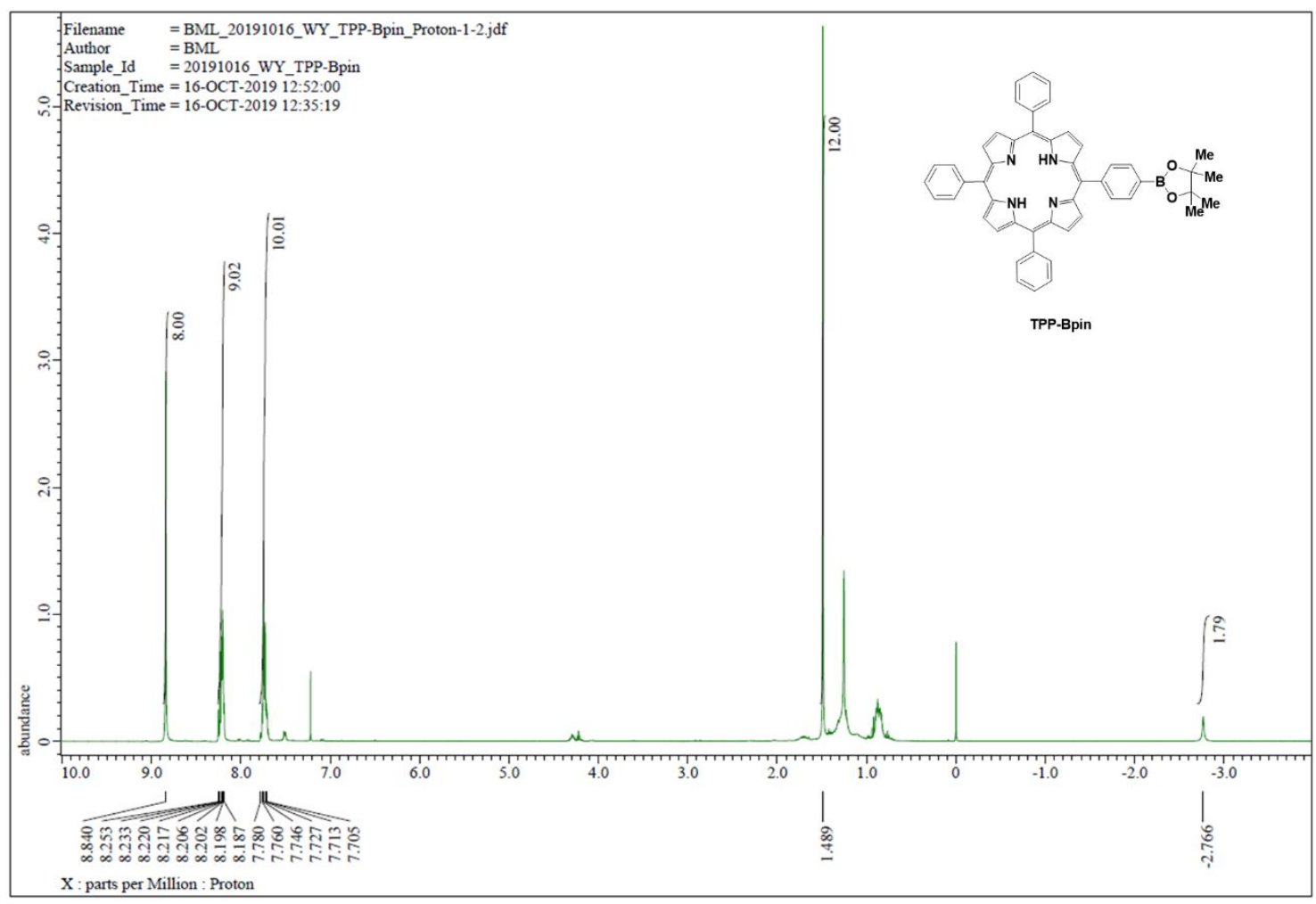

Figure S21. ${ }^{1} \mathrm{H}$ NMR spectrum of TPP-Bpin.

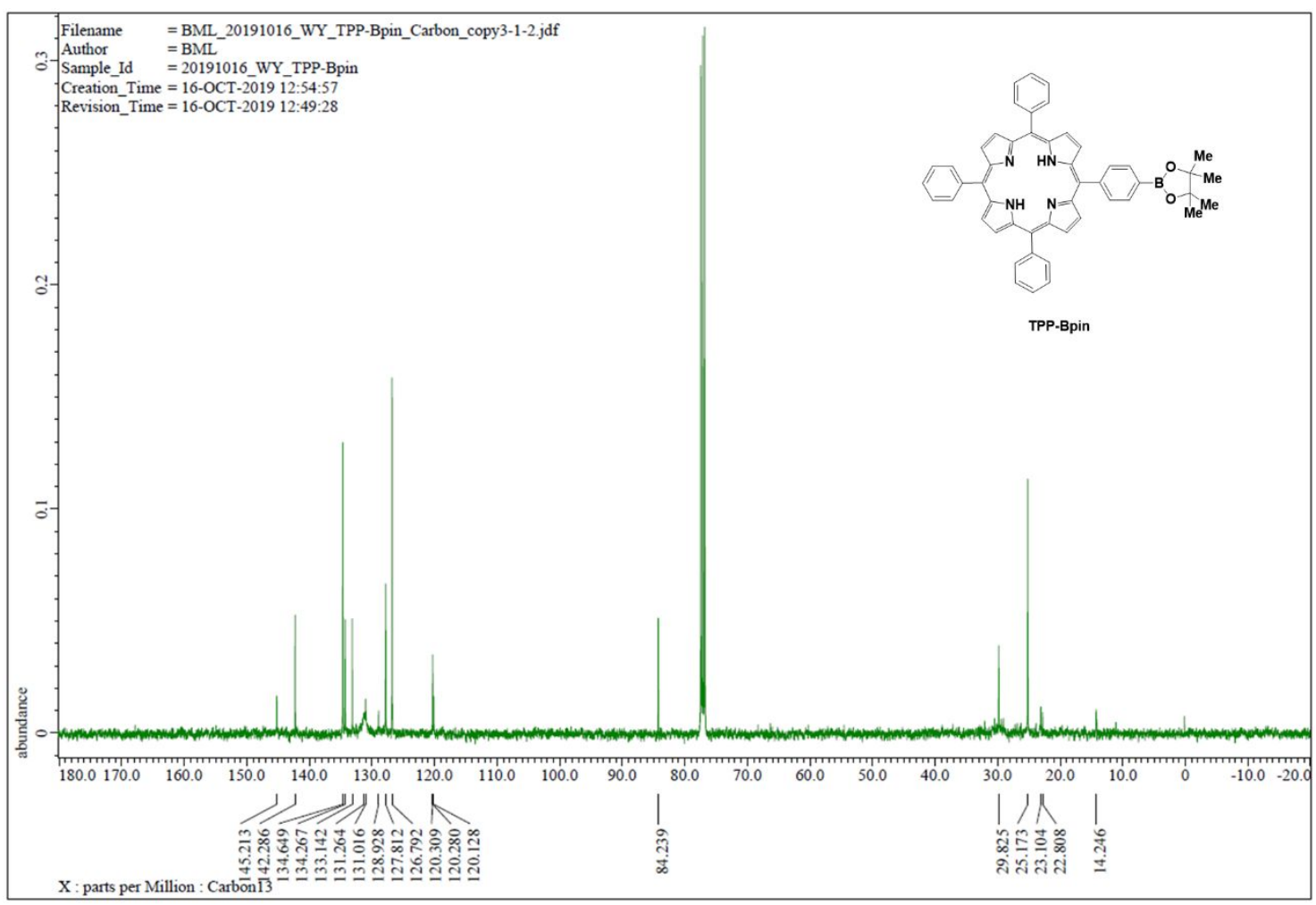

Figure S22. ${ }^{13} \mathrm{C}\left\{{ }^{1} \mathrm{H}\right\}$ NMR spectrum of TPP-Bpin. 